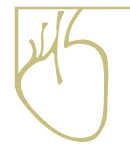

\title{
In Memoriam: Dr. Eduardo Guarda Salazar
}

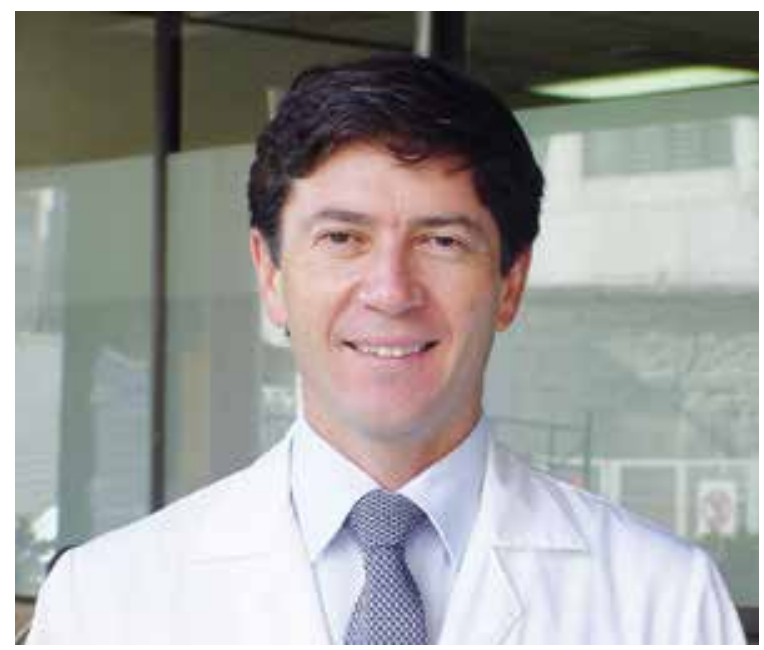

Cuando nos deja una persona que ha sido un académico muy destacado, ha contribuido en forma sobresaliente al desarrollo de una Universidad, ha estado profundamente involucrado con nuestra Sociedad Chilena de Cardiología y Cirugía Cardiovascular y ha sido un motor del desarrollo de esta Revista, una profunda sensación de pérdida invade a todos los que lo conocimos de cerca. Tal ha sido el caso con el reciente fallecimiento del Dr. Eduardo Guarda Salazar. Particular impresión ha rodeado su partida, motivada por una enfermedad que aparece en forma muy inesperada, misteriosa y muy penosa.

Destaquemos hechos relevantes de su trayectoria. Una formación en la Universidad de Chile, en hospitales que han marcado a muchos médicos universitarios, como la Cátedra de Medicina del Hospital del Salvador, lugar donde se le destacó con el Premio "Dr. Hernán Alessandri” como Residente Destacado. Obtuvo una Beca de la Fundación Gildemeister en Investigación Cardiovascular en el Depto de Enfermedades Cardiovasculares y la Facultad de Ciencias Biológicas de la P. Universidad Católica de Chile. En su beca de Post Doctorado en la Universidad de Missouri-Columbia, donde fue becado del Dr. Karl Weber, un importante colaborador de actividades científicas en Chile, obtuvo un Premio al Investigador Joven de la American Heart Association. En una visita del Dr. Karl Weber al Departamento de Enfermedades Cardiovasculares, fueron entusiastas sus palabras para referirse a la calidad académica y el potencial de investigación del Dr. Guarda. A su vuelta a Chile contribuyó decisivamente al desarrollo de la investigación en el área del colágeno en diversas patologías cardiovasculares.

Pero fue su relación con Cardiología de la Universidad Católica el centro de la actividad de Eduardo. Allí recibió su formación como cardiólogo, destacando posteriormente en actividades de docencia e investigación. Muchos de nuestros becados se formaron bajo su exigente jefatura. Para ellos, la figura del Dr. Guarda representó la de una persona con mano firme, innovador y apoyador. Su inquietud tecnológica lo llevó rápidamente a involucrarse con la hemodinámica, donde contribuyó al desarrollo de los primeros pasos en imagenología intravascular coronaria. Su capacidad para conducir procesos de desarrollo académico hizo que en 2014 sus colegas en la División de Cardiología expresaran muy mayoritariamente su apoyo para que se transformara en el Jefe de la División. Diversos proyectos 
de desarrollo para la Cardiología UC quedaron en bosquejos que su enfermedad truncó.

Su interés por la Escuela de Medicina hizo que sus autoridades buscaran rápidamente contar con su colaboración. Tuvo un importante rol en el manejo de la Escuela como Sub-Director de Pregrado y en las modificaciones al Currículo de la carrera de Medicina. Todo auguraba que allí comenzaba un camino que lo llevaría a responsabilidades más altas en la Facultad, pero al darse cuenta de que ese camino lo alejaría de su inquietud fundamental y, en particular de la práctica de la hemodinamia, lo hicieron volver a sus ámbitos de origen. Seguramente esta decisión, muy respetada por cierto, puede haber ha sido considerada como un "pérdida" para la administración académica en la Facultad.

El compromiso del Dr. Guarda con la Sociedad Chilena de Cardiología y Cirugía Cardiovascular fue constante y significativo, al desempeñarse como Director de numerosos Cursos de intra y extra congresos, como Presidente de los Comités de Educación Continua y del Comité Científico, y también como Secretario General del XXXIII Congreso de la Sociedad.

Uno de los proyectos en que Eduardo Guarda puso más empeño fue el desarrollo de ésta, la Revista Chilena de Cardiología. Una impresión compartida por muchos socios y, en ocasiones también por Directorios de la Sociedad, indicaba que la revista no tenía mayor potencialidad para ser una publicación propiamente científica. Muchos llegaron a pensar que su destino no sería otro que un medio de comunicación entre la Sociedad de Cardiología y Cirugía Cardiovascular y su entorno: un medio comunicacional de la Sociedad, de actividades de educación continua y para reflejar la actividad de los congresos. Eduardo nunca compartió esta impresión y, con la tenacidad y eficiencia que lo caracterizaban, hizo todo lo posible para mejorar el funcionamiento secretarial y administrativo de la Revista. Emprendió la difícil tarea de motivar a los autores nacionales a publicar en la Revista, recurriendo a la comunicación personal y al apoyo que él y sus colaboradores les ofrecieron. Un hito fue lograr que la Revista fuera incorporada a la base de publicaciones SciElo, cumpliéndose los requisitos de ingreso y aquellos que permiten su permanencia en el tiempo. Una buena tarea para quienes lo sucederán. Es cierto que Eduardo era una persona reservada, con una mirada escrutadora y a quien costaba llegar a conocer. A los que tuvimos esa suerte, sin embargo, se nos develó un hombre extraordinariamente inteligente, creativo y con la capacidad de trabajar firme para el futuro, con rara habilidad para cumplir las exigentes metas que el mismo se imponía. Pero también, como un amigo entrañable. En nuestro recuerdo quedarán muy presentes los duros momentos que enfrentaron sus hijos y su esposa acompañados, afortunadamente, por buenos amigos que compartieron su pena. Para varios de nosotros ha sido revelador que, al tener que atender a algunos pacientes que lo buscaron sin encontrarlo, pudimos apreciar que también en este aspecto, el despertar el afecto de los enfermos, Eduardo mostró notables condiciones humanas. Ellos y nosotros lo echaremos de menos.

\author{
Dr. Gastón Chamorro, \\ Co-editor Revista Chilena de Cardiología. \\ Dr. Alejandro Martínez, \\ Presidente Sociedad Chilena de Cardiología \\ y Cirugía Cardiovascular.
}

